
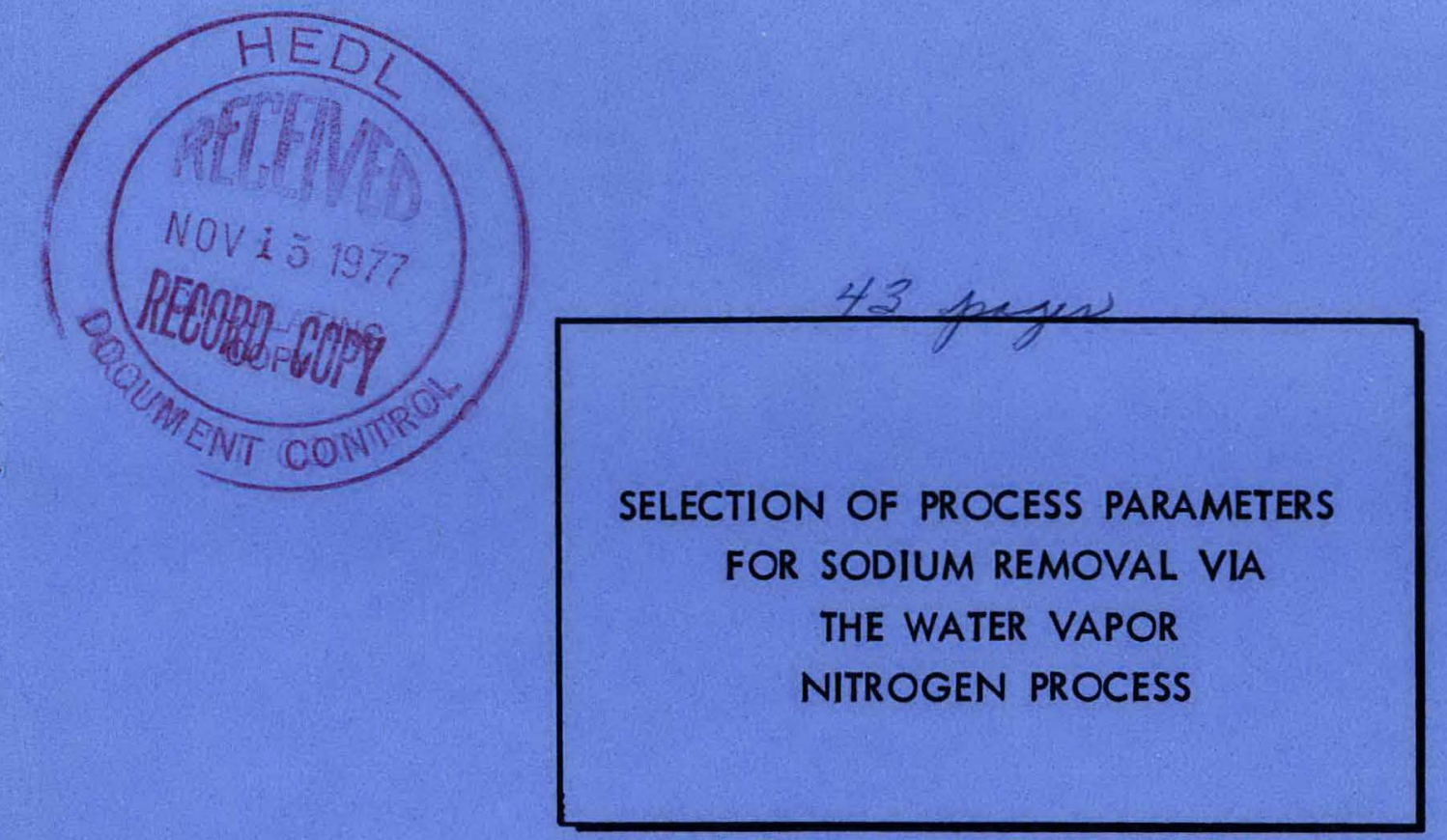

HEDL TME $77-62$

UC-79

$11-77$

1

\title{
SELECTION OF PROCESS PARAMETERS
}

FOR SODIUM REMOVAL VIA

THE WATER VAPOR

NITROGEN PROCESS
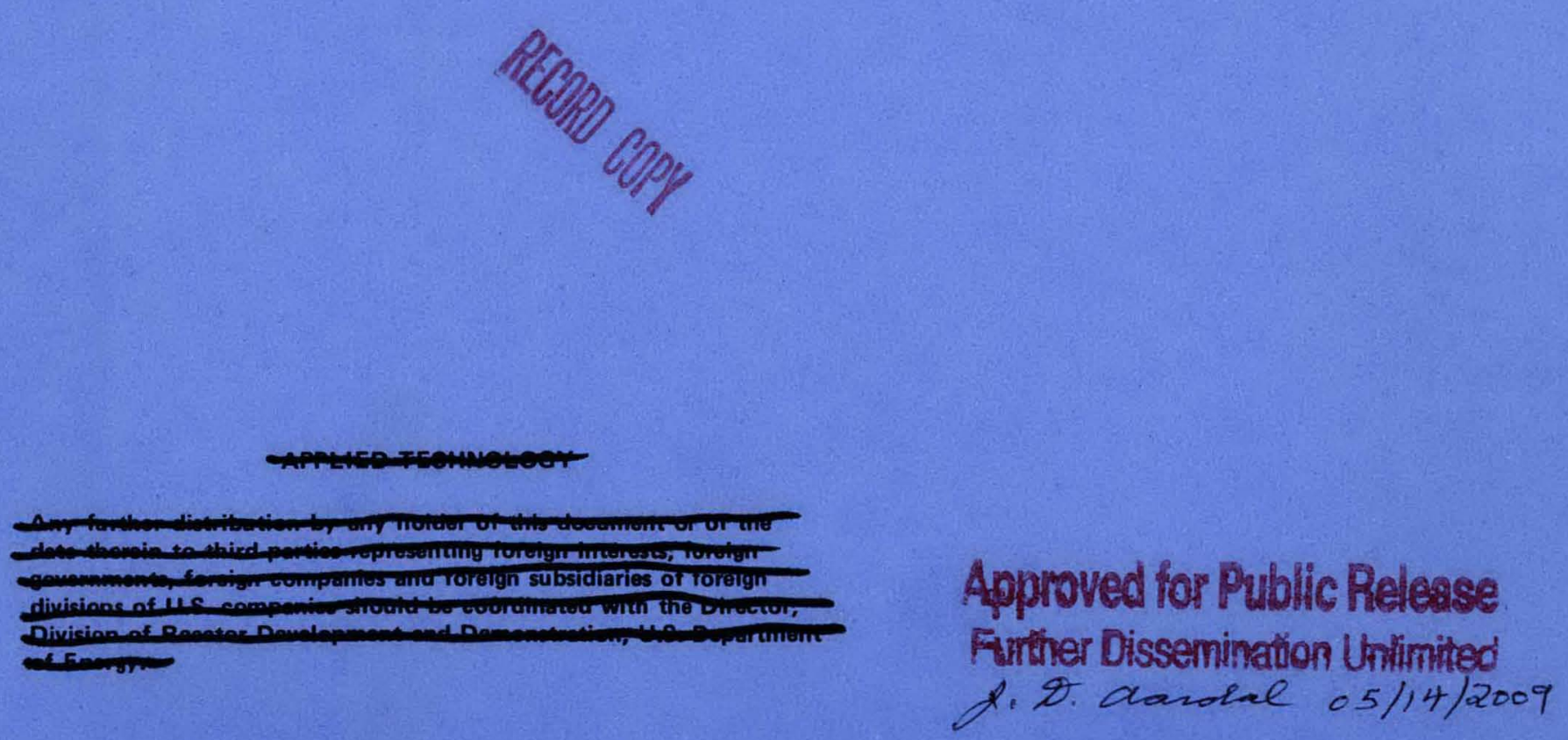

HANFORD ENGINEERING DEVELOPMENT LABORATORY

P.O. Box 1970 Richland, WA 99352

Operated by Westinghouse Hanford Company

A Subsidiary of Westinghouse Electric Corporation

Prepared for the U.S. Department of Energy

under Contract No. EY-76-C-14-2170 


\section{NOTICE}

This report was prepared as an account of work sponsored by the United States Government. Neither the United States nor the U.S. DOE, nor any of their employees, nor any of their contractors, subcontractors, or their employees, makes any warranty, express or implied, or assumes any legal liability or responsibility for the accuracy, completeness or usefulness of any information, apparatus, product or process disclosed, or represents that its use would not infringe privately owned rights.

Printed in the United States of America Available from

DOE Technical Information Center

P. O. Box 62

Oak Ridge, Tenn. 37830

Price: Printed Copy $\$ \underline{4.50}$ 
Form ERDA 426

$(2 \pi 5)$

ERDAM 320
U. S. ENERGY RESEARCH \& DEVELOPMENT ADMINISTRATION

MAJOR CONTRACTOR'S RECOMMENDATION FOR DISPOSITION OF SCIENTIFIC AND TECHNICAL DOCUMENT

- See instructions on Reverse

1. ERDA Report No HEDL-TME-77-62

3. Titie

2. Subject Category No.

UC -79

SELECTION OF PROCESS PARAMETERS FOR SODIUM REMOVAL VIA THE WATER VAPOR NITROGEN PROCESS

4. Type of Document (" $x$ " one)

W. Scientific and rechnical Report

$\square$ b. Conference paper:

Titte of conference

Date of conference

Exact location of conference

c. Other (Specify, Thesis, Translation. etc.)*

5. Copies Transmitted (" $x$ " one or more)

a. Copies being transmitted for standard distribution by ERDA-TIC.

$\square$ b. Copies being transmitted for special distribution per attached complete address list.*

$\square$ c. Two completely legible, reproducible copies being transmitted to ERDA.TIC.

6. Recommended Distribution (" $x$ " one)

Y a. Normal handling (after Patent clearance): no restraints on distribution except as may be required by the security classification.

$\square$ b. Make available only to U.S. Government agencies and their contractors.

$\square$ c. Make available only within ERDA and to ERDA contractors.

$\square$ d. Make available only within EROA.

$\square$ e. Make available only to those listed in item 12 below.

$\square$ t. Other (Specify)*

7. Recommended Arinouncement (" $x$ " one)

Q. Normal procedure mäy be followed.*

$\square$ b. Recommend following announcement limitations:

8. Reason for Restrictions Recommended in 6 or 7 above.

$\square$ a. Preliminary intormation.

$\square$ b. Prepared primarily for internal use.

$\square$ c. Other (Explain)

9. Patent Clearance (' $X$ " one)

a. EROA patent clearance has been granted by responsible EROA patent group.

$\square$ b. Document has been sent to responsible EROA patent group for clearance.

10. National Security information (For clossified document only: " $X$ " one)

$\square$ a. Document does contain national security information other than restricted data.

$\square$ b. Document does not contain national security information other than restricted data.

11. Copy Reproduction and Distribution

a. Total number of copies reproduced

b. Number of copies distributed outside originating organization 9

12. Additional Information or Remarks (Continue on separate sheet, if necessary)

\section{UNCLASSIFIED}

Approved tor Public Release

APPLIED TECHNOLOGY

\section{Futher Dissemination Intimited}


UC-79 (181)

DOE HDQ (2)

Program Divisicn Director

DOE-RL (2)

Manager

Chief Patent Attorney -

FFTF-PO (5)

R.L. Ferguson $V$

HEDL (27)

J.M. Atwood

J.L. Ballif

W.F. Brehm

R.J. Cash

M.D. Crippen

E.A. Evans

C.W. Funk

C.E. Linderoth

J.M. Lutton

J. Marshall

J.J. McCown

L.D. Muhlestein

W.F. Sheely

$W / C-25$ (2)

W/C $-45-$

324/TR6

W/A-11

W/A-32

$W / C-16$

$W / C-53 \checkmark$

$\mathrm{W} / \mathrm{B}-74$

$W / C-51$

$W / B-84$ (2)

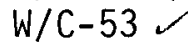

W/A-11

W/C-44

Central Files (10)

Publication Services (2) 
SELECTION OF PROCESS PARAMETERS

FOR SODIUM REMOVAL VIA

THE WATER VAPOR

NITROGEN PROCESS

\section{Monte Crippen}

November 1977

\section{Hanford Engineering Development Laboratory}




\title{
SELECTION OF PROCESS PARAMETERS FOR SODIUM REMOVAL VIA THE WATER VAPOR NITROGEN PROCESS
}

\author{
Monte Crippen
}

\begin{abstract}
This report reviews the water vapor nitrogen (WVN) process for removing sodium from stainless steel equipment, with emphasis on the basis for selecting final operating parameters. The process includes vapor treatment with 5\% water at $160^{\circ} \mathrm{F}$ to $190^{\circ} \mathrm{F}$, hot water rinsing, and hot gas drying.
\end{abstract}




\section{CONTENTS}

\section{Page}

LIST OF ILLUSTRATIONS

vii

LIST OF TABLES

vii

I. INTRODUCTION

A. Purpose 1

B. Summary 1

II. VAPOR PROCESSING 3

A. Historic Evolution 3

B. Present Parameters 15

C. Extended Range of Variables 19

III. RINSING 21

A. Crevice Studies 21

B. Rinse Studies 25

C. Parameters 26

$\begin{array}{ll}\text { IV. DRYING } & 29\end{array}$

A. Theoretical Considerations 29

B. Equipment Experience 30

C. Parameters 32

REFERENCES 33 


\section{ILLUSTRATIONS}

Figure

Page

1. WVN Phase Diagram

2. SRDA Bulk Sodium Water Vapor Reaction - Steady State and Specified Operating Conditions

3. SRDA Bulk Sodium Water Vapor Reaction - Steady State and Specified Operating Conditions

4. Reaction Rate of Sodium - Water Vapor Within Specified Operating Limits of $7.5-15 \% \mathrm{H}_{2} \mathrm{O}$ and $140-160^{\circ} \mathrm{F}$ Inlet

5. The Maximum Expected Sodium Temperatures for Various Pot Diameters and Wa11 Thicknesses

6. Hypothetical Programmed Feed Reaction History 12

7. Typical Hydrogen and Temperature History of Pot Run 14

8. Time Required to Remove $100 \%$ of Sodium from 13-Mi1 Gap Crevices

9. Removal of Sodium from 1-Mil Radial Crevice with Hot $\left(180^{\circ} \mathrm{F}\right.$ to $\left.200^{\circ} \mathrm{F}\right)$ Liquid Water

TABLES

1. Comparison of the Atomized Water and the Water Vapor Process

2. SRDA Run Results Within Stable Envelope of Figure 1

3. SRDA Run Results Within Specified Operating Limits $\left(7.5-15 \% \mathrm{H}_{2} \mathrm{O}, 140-160^{\circ} \mathrm{F}\right)$ Inlet

4. WVN Process Variables and Control Criteria 16

5. Effective Sodium Removal from Crevices with 4-hr Exposure 24

6. Effective Sodium Removal from 13-Mil Crevices for Various Times

7. Results of SRDA Drying Mode Tests 


\section{INTRODUCTION}

A. PURPOSE

This document presents the background for technical decisions that led to the selection of the water vapor nitrogen (WVN) process parameters. Information provided will guide the facility designers and operators in process applications.

The report includes the rationale for selected standard parameters and shows where variations in the standard process may be made within limits of experimental work. The WVN process has not been optimized; there are areas where improvements can be made if additional development is undertaken. For those interested in details, several specific references on experiments are given on each topic.

\section{B. SUMMARY}

For the vapor phase of the WVN process, the $160-190^{\circ} \mathrm{F}$ operating temperature 1 imit was we 11 within the $145-208^{\circ} \mathrm{F}$ minimum/maximum range. Expansion of the temperature range to decrease process time is not expected to aid processing. A water vapor concentration of $5 \%$, in combination with temperature increases to control oscillation, was shown to produce stable, effective processing. The most productive area for improvement would be to increase the water vapor concentration though confirmatory testing would be required.

The rinsing process was controlled mainly by component crevice geometry. Improvements in rinse time may be made by increasing the water temperature, but the concern over the caustic stress corrosion cracking limits the available increase. Although directed jets or sprays for rinse flows were not recommended, methods were suggested for conserving rinse water. 
Drying (as well as heating and cooling) of components was also affected by individual geometry and not processing parameters. Gas-only, vacuum-only, or gas-vacuum combination were shown to be generally accepted methods. The hot-gas-only mode was recommended for its simplicity. 


\section{VAPOR PROCESSING}

\section{A. HISTORIC EVOLUTION}

\section{Theory}

In reviewing the conditions necessary for a water vapor reaction with sodium, it is instructive to examine the temperature-concentration diagram in Figure 1.

To maintain a gaseous solution of a liquid, its partial pressure in the gas phase must be less than its vapor pressure at a given temperature. Therefore, a homogeneous phase will result only with the concentration and temperature above the 1 ine $A B$; below $A B$ a two phase "rain" or "fog" situation will exist. The region $A B C$ will then be the atomized water system which will be discussed separately.

When sodium reacts with water vapor, sodium hydroxide is formed on the metal surface. The caustic so produced absorbs water to form a solution, the contained water subsequently reacting with additional sodium. If, at a given temperature, the partial pressure of water in the gas phase is less than the vapor pressure of water over the caustic solution, the transfer of water will be from the liquid to the gas phase. This reaction is just the opposite of what is desired. The lines DE and FG indicate equilibrium vapor pressures of typical caustic solutions. (1) The dotted line to the left indicates the vapor pressures of saturated solutions, to the left of which no liquid can exist. Thus, in order to react to the sodium, the temperature and composition must be to the right of the region roughly delineated by DHFG.

Two other restraints are also indicated, the first being a minimum temperature. If the reaction is carried out below ambient, a cooling or refrigeration system is needed. Further, the maximum water concentration 
is rather low and, since reaction rate generally increases with both temperature and concentration, low process temperatures seemed unwarranted. Therefore, ambient temperature was selected as the lower processing limit (line FA on Figure 1). The second restraint was the upper temperature limit. It appeared prudent to stay below the melting point of sodium (1ine GB on Figure 1) to prevent changes in the metal configuration during processing. This also allowed very high water concentrations to be reached. Therefore, the values of the temperature and concentration parameters should be maintained within the area ABGFHD in Figure 1 for the gas phase WVN.

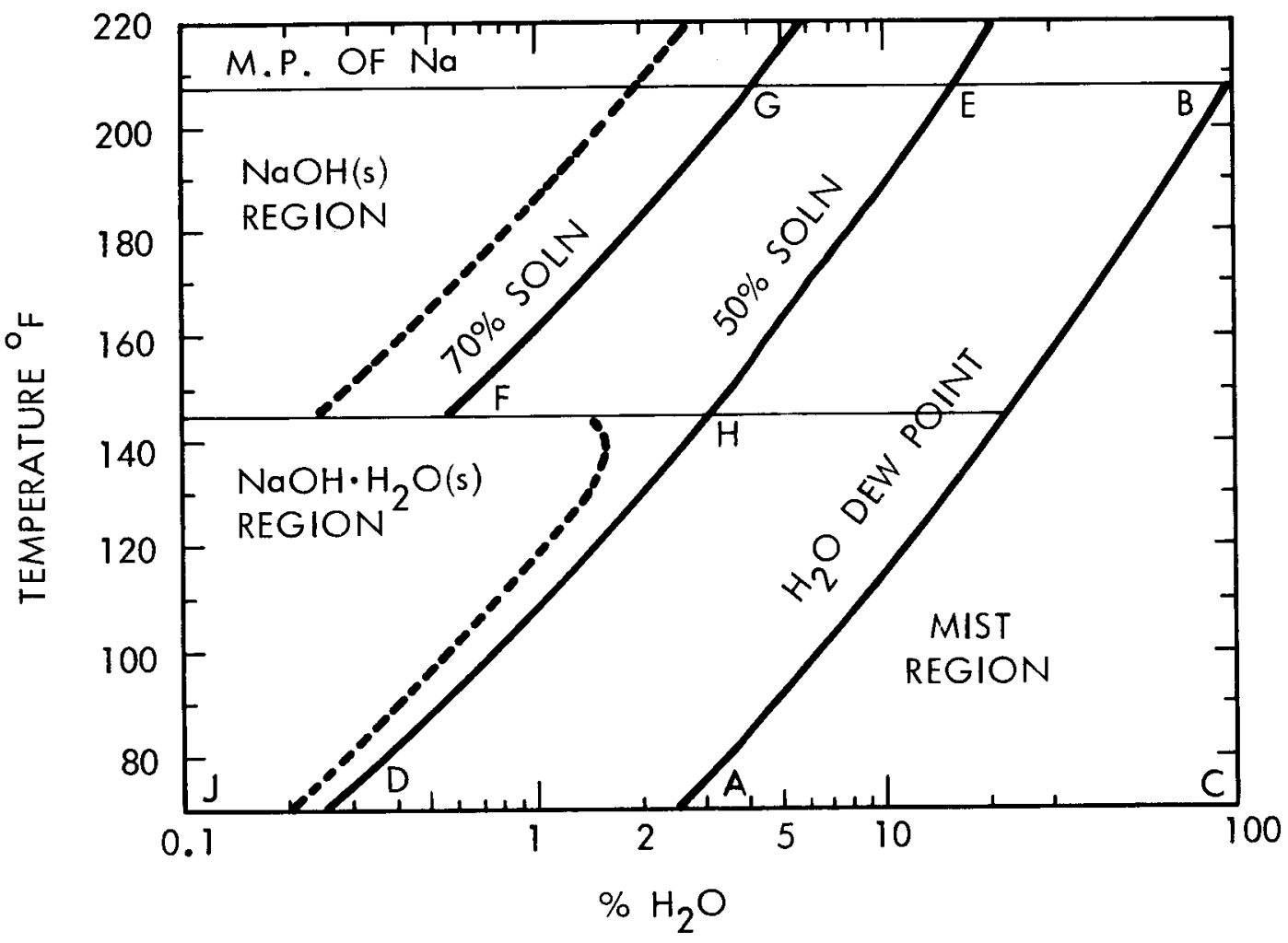

FIGURE 1. WVN Phase Diagram. 


\section{Water Mist}

During 1973 a number of experiments were carried out in plastic bags and glass columns using the atomized water process. The initial tests resulted in high temperature spikes and generally unstable reactions while the latter tests were better controlled to prevent direct impingement of the atomized water on the test pieces. However, unstable reactions still occurred because condensing water droplets fell onto large sodium surfaces. The results are summarized in Table 1 . This led to the conclusion that containment vessel wall heaters should be used to prevent condensation.

In identical comparison runs between the atomized water and WVN processes, the WVN showed better control and faster processing. Therefore, the atomized water process was abandoned in favor of WVN.

\section{TABLE 1}

\section{COMPARISON OF THE ATOMIZED WATER AND THE WATER VAPOR PROCESS}

\begin{tabular}{|c|c|c|c|c|c|c|c|c|c|c|c|}
\hline \multirow[b]{2}{*}{$\begin{array}{c}\text { Run } \\
\text { Number }\end{array}$} & \multicolumn{4}{|c|}{ FEED } & \multicolumn{3}{|c|}{ RECIRCULATION } & \multicolumn{4}{|c|}{ RESULTS } \\
\hline & $\begin{array}{l}N_{2}(g) \\
(\ell / h r) \\
\end{array}$ & $\begin{array}{l}\mathrm{H}_{2} \mathrm{O}(\mathrm{)} \\
(\mathrm{l} / \mathrm{hr}) \\
\end{array}$ & $\begin{array}{c}\mathrm{H}_{2} \mathrm{O}^{\mathrm{N}} \mathrm{N}_{2} \\
\text { Mole } \\
\text { (Percent) } \\
\end{array}$ & $\begin{array}{l}\text { Temp } \\
\left({ }^{\circ} \mathrm{F}\right) \\
\end{array}$ & $\begin{array}{l}\text { Total } \\
\text { Flow } \\
\text { l/hr } \\
\end{array}$ & $\begin{array}{l}\mathrm{H}_{2} \mathrm{O} \\
\underline{\ell / h r} \\
\end{array}$ & $\begin{array}{c}\mathrm{H}_{2} \mathrm{O} / \mathrm{N}_{2} \\
\text { Mole } \\
\text { (Percent) } \\
\end{array}$ & $\begin{array}{l}\text { Run } \\
\text { Time } \\
\text { (hr) }\end{array}$ & $\begin{array}{c}\text { Sodi um-Wet } \\
\text { Surface } \\
\text { hr to Remove } \\
\end{array}$ & $\begin{array}{c}\text { 3-in. Tong } \\
\text { 13-mils gap } \\
\text { (Estimated } \\
\text { Percent } \\
\text { Na Removed) } \\
\end{array}$ & $\begin{array}{c}5 \mathrm{~g} \mathrm{Na} \\
\text { Estimated } \\
\text { Reacted } \\
\end{array}$ \\
\hline \multicolumn{12}{|c|}{ ATOMI ZED WATER PROCESS } \\
\hline 1 & 660 & $\begin{array}{l}0.492 \\
(1 \text { iq })\end{array}$ & 48 & RT & 2220 & 0.033 & 6 & 48 & 2 & $\begin{array}{l}60 \% \text { in } 48 \mathrm{hr} \\
0.02 \mathrm{in.} / \mathrm{hr}\end{array}$ & $\begin{array}{l}60 \mathrm{mils} \\
\text { depth in } \\
48 \mathrm{hr}\end{array}$ \\
\hline 2 & 660 & $\begin{array}{l}0.732 \\
(1 \mathrm{iq})\end{array}$ & 58 & RT & 8880 & 0.087 & 16 & 25 & 2 & $22 \%$ in $25 \mathrm{hr}$ & $\begin{array}{l}\text { Spike } \\
>500^{\circ} \mathrm{F} \\
\text { Reaction } \\
\text { incomplete }\end{array}$ \\
\hline \multicolumn{12}{|c|}{ WATER-VAPOR-NITROGEN PROCESS } \\
\hline $\begin{array}{l}1 \\
\text { concurrent } \\
\text { with Run } 2 \\
\text { above }\end{array}$ & 1080 & $\begin{array}{l}54 \\
\text { (gas) }\end{array}$ & $5^{(a)}$ & $\begin{array}{l}150- \\
170\end{array}$ & 0 & 0 & 0 & 25 & 3 & $\begin{array}{l}75 \% \text { in } 25 \mathrm{hr} \\
0.05 \mathrm{in.} / \mathrm{hr}\end{array}$ & $\begin{array}{l}\text { Reaction } \\
\text { complete }\end{array}$ \\
\hline $\begin{array}{l}2 \\
\text { concurrent } \\
\text { with Run } 3 \\
\text { above }\end{array}$ & 1080 & $\begin{array}{l}54 \\
\text { (gas) }\end{array}$ & $5^{(a)}$ & $\begin{array}{l}150- \\
170\end{array}$ & 0 & 0 & 0 & 56 & 4 & $\begin{array}{l}100 \text { in } 56 \\
\mathrm{hr} ; 70.03 \\
\text { in. } / \mathrm{hr}\end{array}$ & $\begin{array}{l}\text { Reaction } \\
\text { complete }\end{array}$ \\
\hline
\end{tabular}




\section{Window}

The previously mentioned area in Figure 1 was explored by a number of test runs in the Sodium Removal Development Apparatus (SRDA) using most7y 4-in. diameter, nondrainable pools of sodium. The following criterion for the success of a run was selected: If the reaction was completed without a temperature excursion (or spike) over $250^{\circ} \mathrm{F}$, the run was successfut. The $250^{\circ} \mathrm{F}$ limit was selected because that was expected to be below the minimum temperature needed to initiate caustic stress corrosion cracking in stainless steel.

A few dozen preliminary runs showed that the area $A B C D E$ of Figure 2 always gave uncontrolled and unsuccessful runs. The spikes were often above $500^{\circ} \mathrm{F}$ for tens of minutes or longer. However, within the area AEF of Figure 2, the runs were usually successful -- although there were occasional temperature excursions over $250^{\circ} \mathrm{F}$, they lasted only a few minutes. Some runs were conducted at temperatures as $10 \mathrm{w}$ as $100^{\circ} \mathrm{F}$ and were successful, but the reaction rate was very slow. Typical data are shown as Figure 3 and Tables 2 and 3.

At this point, several conclusions were drawn: A successful operating envelope of parameters had been found, and changes in the temperature or concentration during the reaction almost always upset the reacting mass and led to spikes.

More runs were made and the stable area was cropped to HIJH (see Figure 2). The limits (or window) for the process were formally set as area KLMNK of Figure $2\left(150^{\circ} \mathrm{F} \pm 10^{\circ}\right.$ and $7.5 \% \pm 2.5 \%$ water $)$. The reaction rate was approximated at $0.02 \mathrm{in.} / \mathrm{hr}$ under these conditions (see Figure 4). 


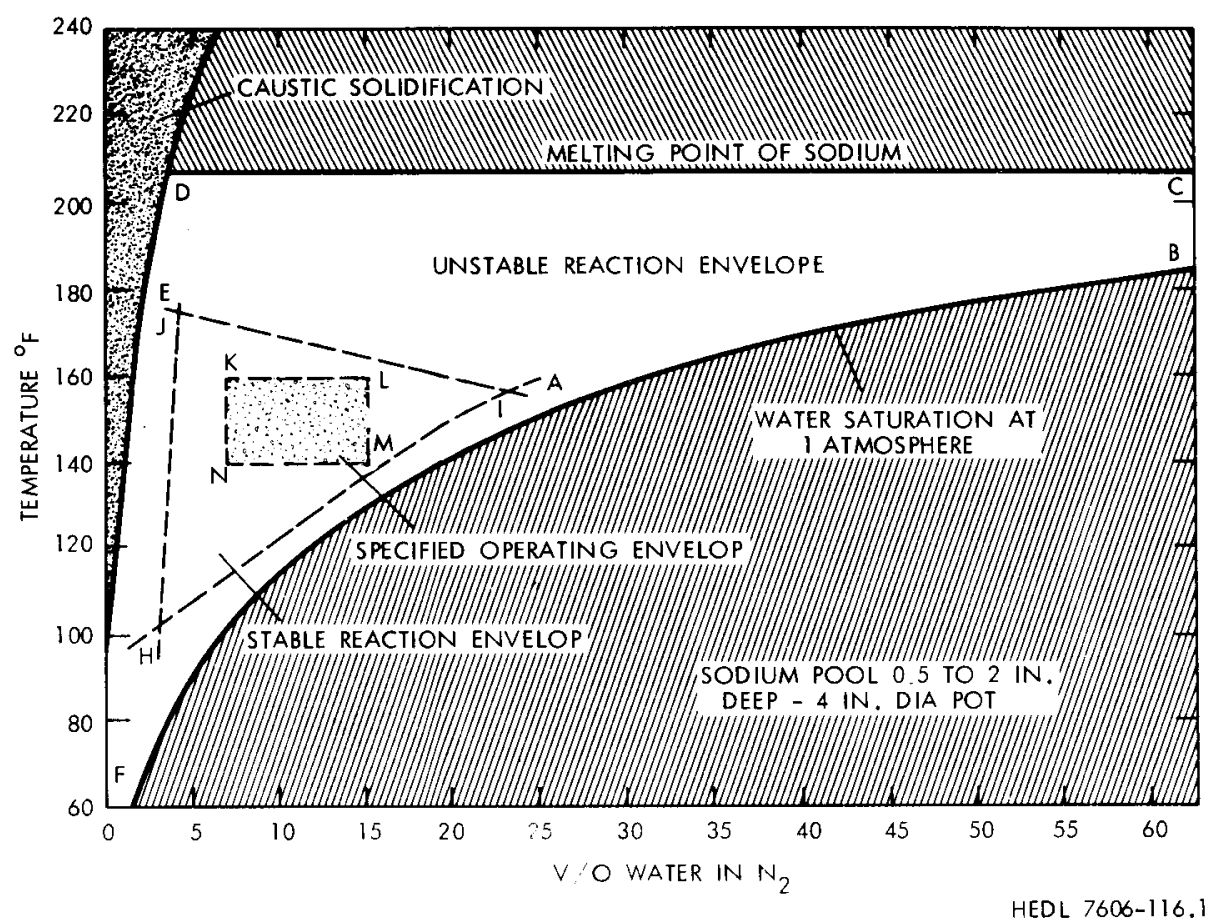

Figure 2. SRDA Bulk Sodium Water Vapor Reaction -- Steady State and Specified Operating Conditions.

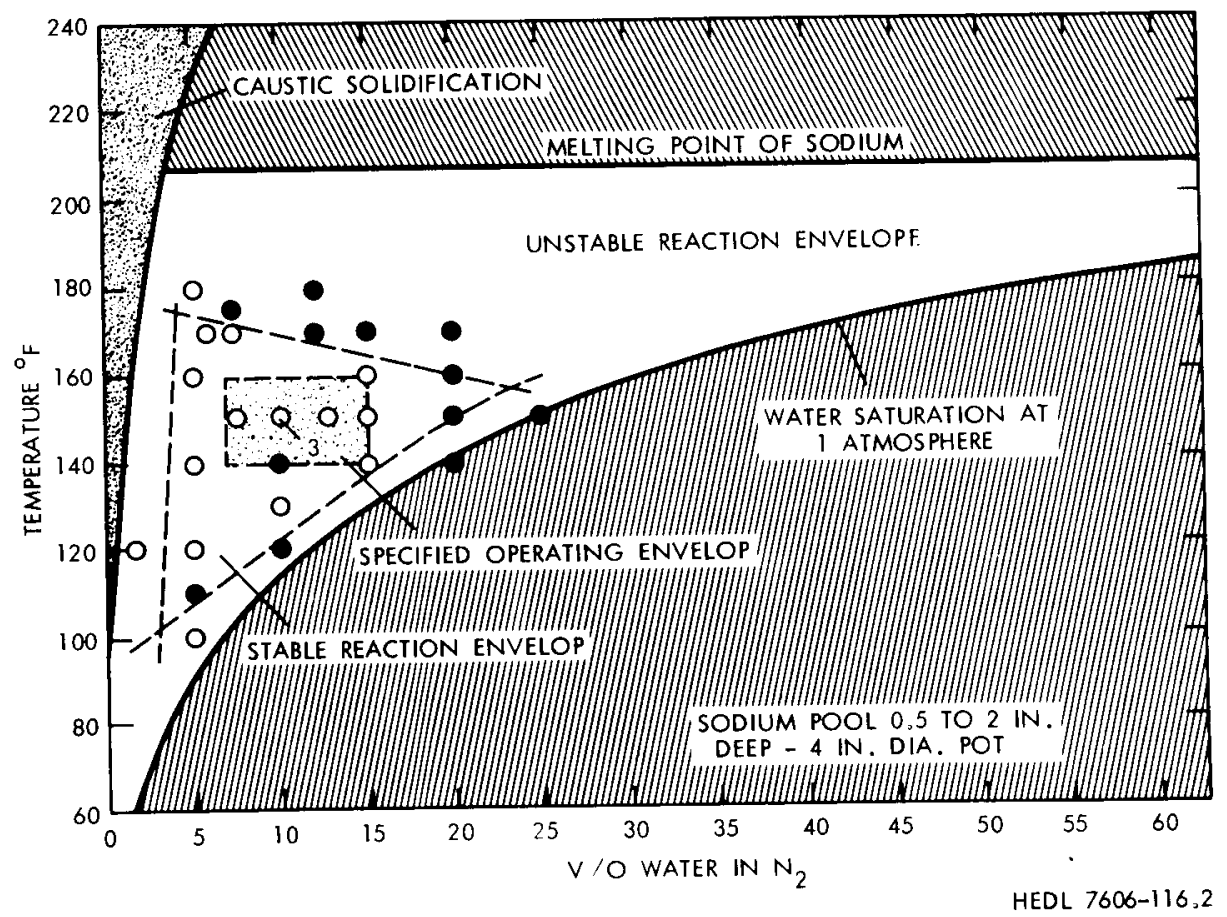

FIGURE 3. SRDA Bulk Sodium Water Vapor Reaction -- Steady State and Specified Operating Conditions. 
TABLE 2. SRDA RUN RESULTS WITHIN STABLE ENVELOPE OF FIGURE 1.

\begin{tabular}{|c|c|c|c|c|c|c|c|}
\hline \multirow[b]{3}{*}{$\begin{array}{c}\begin{array}{c}\text { Run } \\
\text { Number }\end{array} \\
\end{array}$} & \multicolumn{3}{|c|}{ OPERATING CONDITIONS } & \multicolumn{2}{|c|}{ RESULTS } & \multicolumn{2}{|c|}{ POOL CONFIGURATION } \\
\hline & \multirow[b]{2}{*}{$\begin{array}{l}\text { Conclusion } \\
\mathrm{H}_{2} \mathrm{O}(\mathrm{g}) \% \\
\text { Percent } \\
\end{array}$} & \multicolumn{2}{|c|}{ TEMPERATURE } & \multicolumn{2}{|c|}{ TIME } & \multirow[b]{2}{*}{$\begin{array}{l}\text { Sodium } \\
\text { Depth, in. }\end{array}$} & \multirow[b]{2}{*}{$\begin{array}{c}\text { Sodium } \\
\text { Area, in. }\end{array}$} \\
\hline & & $\begin{array}{l}\text { Initial } \\
\mathrm{N}_{2} \text { Inlet } \\
{ }^{\circ} \mathrm{F} \\
\end{array}$ & $\begin{array}{l}\text { Maxtmum } \\
\text { Sodium, }{ }^{\circ} \mathrm{F}\end{array}$ & $\begin{array}{l}\text { To Complete } \\
\text { Reaction, hr }\end{array}$ & $\begin{array}{c}\text { Above } \\
250^{\circ} \mathrm{F}, \mathrm{hr} \\
\end{array}$ & & \\
\hline 3 & 7.5 & 170 & $<250$ & 20 & 0 & 0.5 & 14 \\
\hline 5 & 12 & 150 & $<250$ & 19 & 0 & 0.5 & 14 \\
\hline 8 & 6.0 & 170 & $<250$ & 48 & 0 & 1 & 14 \\
\hline 13 & 15 & 150 & $<250$ & 57 & 0 & 0.5 & 14 \\
\hline 17 & 7.5 & 150 & $<250$ & 60 & 0 & 0.5 & 14 \\
\hline 29 & 5.0 & 120 & $<250$ & 41 & 0 & 0.5 & 14 \\
\hline 32 & 5.0 & 160 & $<250$ & 75 & 0 & 0.5 & 14 \\
\hline 35 & 15 & 140 & $<250$ & 17 & 0 & 0.5 & 14 \\
\hline 36 & 5.0 & 140 & $<250$ & 63 & 0 & 0.5 & 14 \\
\hline 37 & 10 & 130 & $<250$ & 68 & 0 & 0.5 & 14 \\
\hline 39 & 15 & 160 & $<250$ & 26 & 0 & 0.5 & 14 \\
\hline 41 & 10 & 140 & 285 & 32 & 0.16 & 0.5 & 14 \\
\hline 54 & 10 & 150 & $<250$ & 107 & 0 & 2 & 14 \\
\hline 55 & 10 & 150 & $<250$ & 60 & 0 & 1 & 14 \\
\hline 56 & 10 & 150 & $<250$ & 82 & 0 & 2 & 14 \\
\hline 59 & 10 & 150 & $<250$ & 82 & 0 & 2 & 14 \\
\hline
\end{tabular}

TABLE 3. SRDA RUN RESULTS WITHIN SPECIFIED OPERATING LIMITS $\left(7.5-15 \% \mathrm{H}_{2} \mathrm{O}, 140-160^{\circ} \mathrm{F}\right)$ INLET.

\begin{tabular}{|c|c|c|c|c|c|c|}
\hline \multicolumn{3}{|c|}{ OPERATING CONDITIONS } & \multicolumn{2}{|c|}{ RESULTS } & \multicolumn{2}{|c|}{ POOL CONFIGURATION } \\
\hline \multirow[b]{2}{*}{$\begin{array}{l}\text { Conclusion } \\
\mathrm{H}_{2} \mathrm{O}(\mathrm{g}) \% \\
\text { Percent } \\
\end{array}$} & \multicolumn{2}{|c|}{ TEMPERATURE } & \multicolumn{2}{|c|}{ TIME } & \multirow[b]{2}{*}{$\begin{array}{c}\text { Sodium } \\
\text { Depth, in. }\end{array}$} & \multirow[b]{2}{*}{$\begin{array}{c}\text { Sodium } \\
\text { Area, in. } 2 \\
\end{array}$} \\
\hline & $\begin{array}{l}\text { Initial } \\
\mathrm{N}_{2} \text { Inlet } \\
{ }^{\circ} \mathrm{F} \\
\end{array}$ & $\begin{array}{l}\text { Maximum } \\
\text { Sodium, }{ }^{\circ} \mathrm{F} \\
\end{array}$ & $\begin{array}{l}\text { To Complete } \\
\text { Reaction, hr }\end{array}$ & $\begin{array}{c}\text { Above } \\
250^{\circ} \mathrm{F}, \mathrm{hr} \\
\end{array}$ & & \\
\hline 12 & 150 & $<250$ & 19 & 0 & 0.5 & 14 \\
\hline 15 & 150 & $<250$ & 57 & 0 & 1 & 14 \\
\hline 15 & 140 & $<250$ & 17 & 0 & 0.5 & 14 \\
\hline 15 & 160 & $<250$ & 26 & 0 & 0.5 & 14 \\
\hline 10 & 140 & 285 & 32 & 0.16 & 0.5 & 14 \\
\hline 10 & 150 & $<250$ & 107 & 0 & 2 & 14 \\
\hline 10 & 150 & $<250$ & 60 & 0 & 1 & 14 \\
\hline 10 & 150 & $<250$ & 82 & 0 & 2 & 14 \\
\hline 10 & 150 & $<250$ & 82 & 0 & 2 & 14 \\
\hline
\end{tabular}




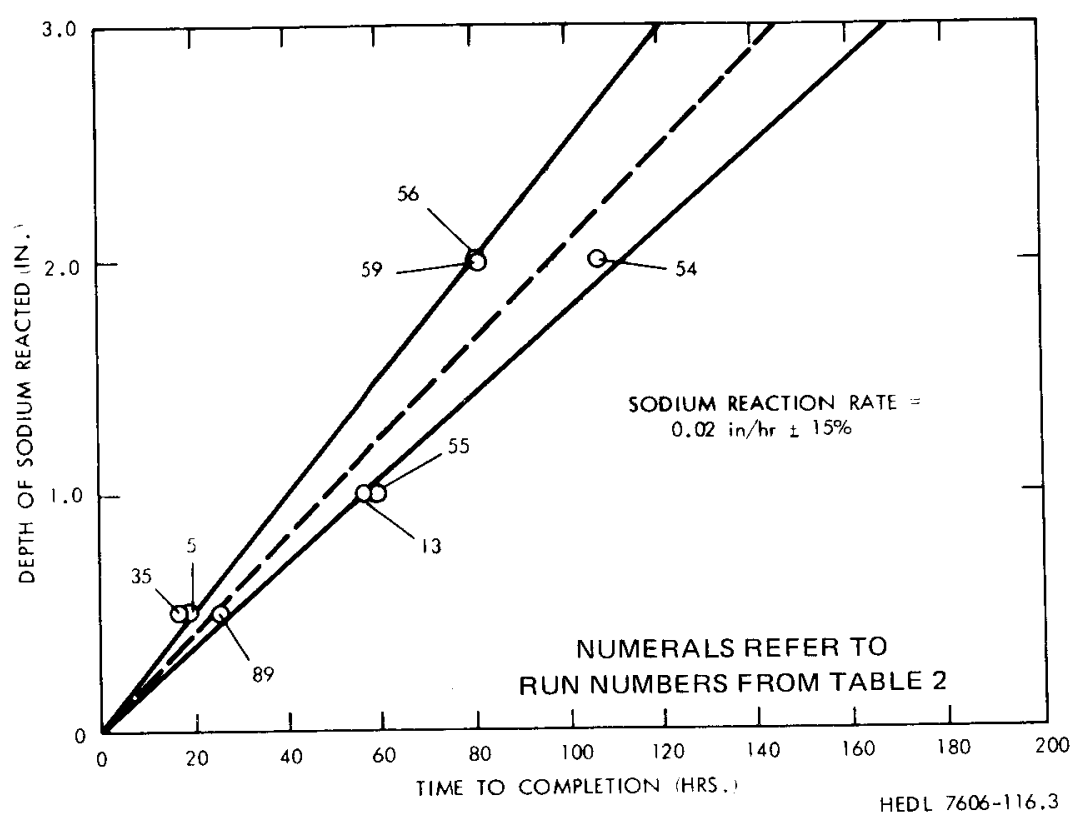

FIGURE 4. Reaction Rate of Sodium -- Water Vapor Within Specific Operating Limits of $7.5-15 \% \mathrm{H}_{2} \mathrm{O}$ and $140-160^{\circ} \mathrm{F}$ Inlet.

It was recognized that some of the unsuccessful runs had probabiy been caused by the nonwetting condition of the pools which was an experimental anomaly. That is, the sodium had been cast into a stainless steel container but not heated enough to wet the steel. During the reaction, the caustic solution crept between the steel and the sodium. When the disc of sodium floated, the reaction surface was greatly increased, the system went unstable, and a spike resulted. To prevent this, all pots were sodium-wetted at $1050^{\circ} \mathrm{F}$ for a minimum of $48 \mathrm{hr}$ after they had been filled with sodium.

This was the origin of the window concept resulting from a first examination of the problem. The undrained pools for these tests were one, two, and four inches in diameter by one-quarter to one inch deep. A continuing test campaign was started using larger diameter pots for scale-up purposes. 
It was soon discovered that larger pools spiked more often than smalier ones even though they were processed within the window. A few runs at other temperatures and concentrations showed that the propensity to spike was higher outside the window area. A great deal of effort was spent analyzing the thermal characteristics of these pools and comparing them to hardware of various sizes. $(2,3)$ Eventually it was found that pools were not appropriate to test since few existed in real hardware and the thermal analogue of large pools never exists in real reactor components (see Figure 5 ). That is, when more sodium surface is available there is also more steel cross section to carry the heat away. Nevertheless, it was considered appropriate to solve the pool problem.

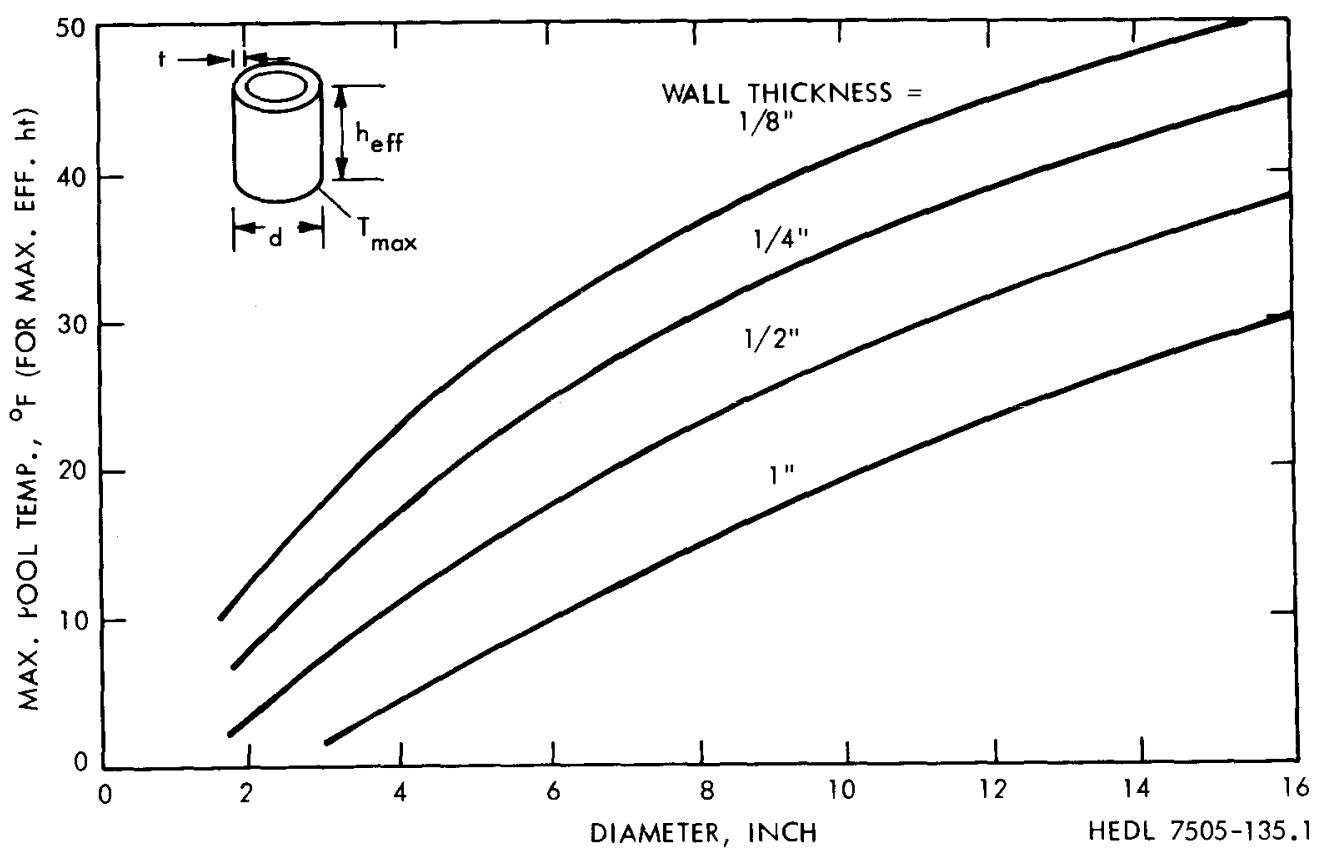

FIGURE 5. The Maximum Expected Sodium Temperatures for Various Pot Diameters and Wall Thicknesses.

4. Programmed Feed

During mid-1974 a test program was initiated to determine the exact chemistry of the system. This was done with small beakers of sodium in 4-in. diam glass pipes. The apparatus eventually allowed the separation 
and rate characterization of the two principal reactions, condensation and consumption, as shown below:

$$
\begin{aligned}
& \mathrm{Na}+\mathrm{NaOH} \cdot\left(\mathrm{H}_{2} \mathrm{O}\right)_{X} \rightarrow(\mathrm{NaOH})_{2} \cdot\left(\mathrm{H}_{2} \mathrm{O}\right)_{x}-1+1 / 2 \mathrm{H}_{2} \\
& \mathrm{NaOH} \cdot\left(\mathrm{H}_{2} \mathrm{O}\right)_{x}+\mathrm{H}_{2} \mathrm{O} \rightarrow \mathrm{NaOH} \cdot\left(\mathrm{H}_{2} \mathrm{O}\right)_{x}+1
\end{aligned}
$$

These reactions allowed observation and quantification of many interesting and useful phenomena that had been either suspected or unknown. Perhaps most important was that the hydrogen product gas could be measured with high precision and at a very small concentration. Where previously only overall average reaction rates were determined, the sodium consumption reaction could now be monitored on a continuing basis with minute-to-minute variations in the reaction clearly detectable.

It was determined that the rate was very rapid during the initial hour or so of pool reaction and then it decreased. It continued stably for some time (many tens of hours), usually until the sodium was consumed to the point that the available reaction area started to decrease significantly. Since the window concept calls for a constant feed rate, it was clear that an inventory of unreacted water could accumulate if condensation was greater than consumption. This situation could eventually lead to a spike.

The concept of programmed feed evolved as a method of decreasing the water feed in anticipation of the expected changes in the reaction rate. This gave a more nearly constant water inventory resulting in a more stable reaction system and fewer spikes. Figure 6 shows that the water inventory will be fairly constant until the end of the reaction. At this point, it is of no particular concern that a theoretical spike may occur. The remaining sodium is so small compared to the solution, a temperature rise would be very modest even with the instantaneous and complete consumption of the sodium inventory. This was observed to be the case experimentally. 


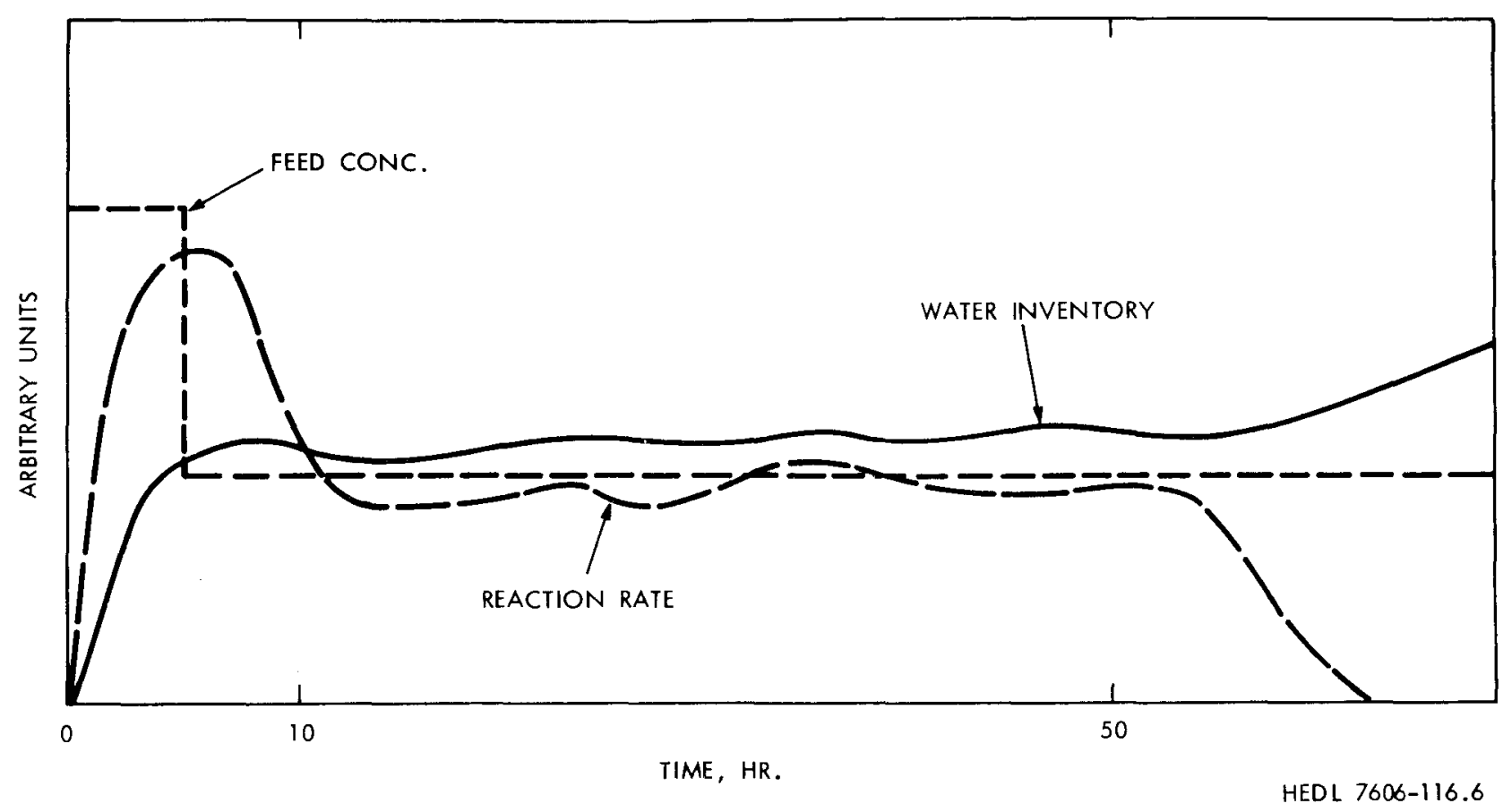

FIGURE 6. Hypothetical Programmed Feed Reaction History.

The results of SRDA tests using programmed feed on 8- and 12-in. diam pots were encouraging and significantly better than had been obtained with constant feed conditions on similar size pools even though there were still some spikes. It was determined that different programs might be required for different configurations and that practice on these configurations would be required for successful application on a large scale. It was also determined that there could be difficulties in getting an exact characterization of real components since the degree of sodium draining could vary in ways unknown to the cleaning operators. Thus, the programmed feed formed a useful, but short duration, stepping stone in the total WVN development. 


\section{Feedback Control}

During late 1974 the work in the glass columns was very productive. As had been suspected from theoretical considerations, the reaction rate was characterized as a power function of the concentration, and the formula was experimentally determined to be:

$$
\text { rate }\left(\frac{i n .}{h r}\right)=0.0018\left(\% \mathrm{H}_{2} 0\right)^{1.2}=\frac{i n .^{3}}{h r-i n .^{2}}
$$

It was also found that the temperature dependency was very slight because the driving force was the difference in partial pressure of water between the gas phase and the caustic phase. As long as the processing condition was above the line $A B$ in Figure 1 , the partial pressure in the gas was independent of temperature, and the partial pressure of the liquid ( 1 ine $D E$ ) was only weakly dependent on temperature. However, the dependency was negative; raising the temperature decreased the reaction rate.

One very important phenomenon was observed. Spikes during a run were always preceded by oscillation in the hydrogen output of the reacting pool. Reexamination of the records on all glass pipe runs confirmed this, and Figure 7 illustrates the phenomenon during a typical run. It also seemed to be true on 11 SRDA runs although the record was not complete because some of the early istrumentation could not detect this phenomenon. Confirmatory runs made in the glass pipe showed that if the process temperature was raised when the hydrogen output started to oscillate, the usually inevitable spike was prevented. Development runs in SRDA showed that the technique was fully applicable on a large scale. (4) In fact, since the initial development was conducted, the method, when properly applied in a timely manner, has never failed to stabilize an undrained sodium pool. This has been continually demonstrated in SRDA and AMCF. 


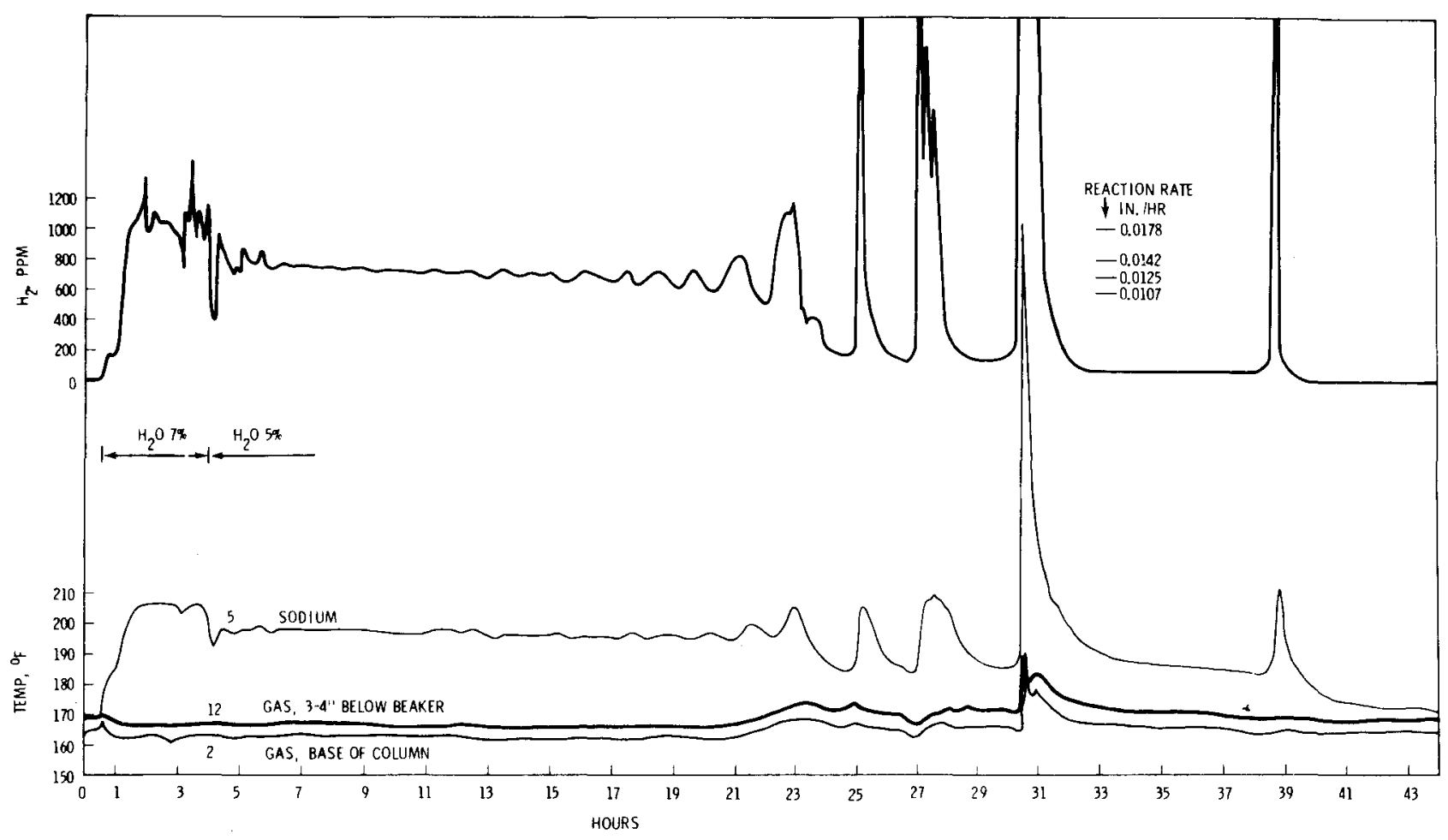

FIGURE 7. Typical Hydrogen and Temperature History of Pot Run.

The criteria for success were tightened at this point. Not only did the temperature have to stay below $250^{\circ} \mathrm{F}$, but also there could be no significant uncontrolled oscillations in the temperature or hydrogen record. These new criteria would have changed the box score on many previous runs from successful to unsuccessful.

These runs showed that at least a $5-7^{\circ} \mathrm{F}$ increase was necessary to effect a change in the reacting system and that $10^{\circ} \mathrm{F}$ always seemed to accomplish the change effectively. Several changes up through the temperature range from $160^{\circ} \mathrm{F}$ to $190^{\circ} \mathrm{F}$ were a 11 effective.

This completes the summary of pertinent points in the development of the WVN Feedback Control concept and leads to enumeration of the present control criteria. This standard calls for the component to be brought to a constant temperature of $160^{\circ} \mathrm{F}$. Steam is then admitted to bring the gas 
concentration up to $5 \%$ where it is held. If instabilities are indicated by oscillations in the hydrogen record, the process temperature is increased by $10^{\circ} \mathrm{F}$ to dampen and eliminate the oscillation. The higher temperature is maintained throughout the remainder of the process unless further increases are required because of more instabilities. When the reaction is complete, the steam concentration is raised for a time as a double check. This completes the gas phase of the process.

\section{B. PRESENT PARAMETERS}

The values of various parameters given in Table 4 are justified in the following subsections:

\section{Equipment}

A recirculating gas system was selected to conserve reactants and to give clear information about the progress of the reaction. An engineering judgment was made that the vessel volume should be changed at least every 5 min to maintain the well-stirred criterion.

Instrument requirements (as far as possible) were selected to utilize off-the-shelf equipment normally available to the chemical process industry.

\section{Procedure}

Experience proved that minute attention to the details of preprocessing, especially as regards draining, frost, possible plugs, reaction time, etc., greatly facilitated the overall cleaning operation.

Inerting is required to decrease the oxygen level below $4 \%$ as this concentration will not support hydrogen combustion under any circumstances. As a matter of practicality, the actual concentration will be much lower. The highly sensitive hydrogen meter, upon which much depends, must read 
TABLE 4

WVN PROCESS VARIABLES AND CONTROL CRITERIA

Unit

Operation/ Media

System Feed

\begin{tabular}{|c|c|c|c|c|c|c|}
\hline Preprocess & $\begin{array}{c}\text { Start } \\
\text { Up }\end{array}$ & $\begin{array}{l}\text { Steady } \\
\text { State }\end{array}$ & $\begin{array}{c}\text { Reaction } \\
\text { Termination }\end{array}$ & $\begin{array}{l}\text { Rinse } \\
\text { Wash }\end{array}$ & Drying & $\begin{array}{l}\text { Allowable } \\
\text { Variation }\end{array}$ \\
\hline
\end{tabular}

Temp ${ }^{\circ} \mathrm{F}$

70 to 400

$\begin{array}{rr}160 & 160 \text { to } 190 \\ 71 & 71 \text { to } 88 \\ 99 & \mathrm{~nm} \\ 1 & 5 \text { to } 10 \\ \mathrm{~nm} & \mathrm{~nm} \\ \mathrm{~nm} & \mathrm{~nm}\end{array}$

$\vec{a}$

Temp ${ }^{\circ} \mathrm{C}$

$$
21 \text { to } 204
$$$$
100
$$

$\mathrm{N}_{2}$ (vol.\%)

0.005

2 (vol \%)

$$
\mathrm{nm}
$$

$\mathrm{O}_{2}$ (vol.\%)

$\mathrm{nm}$

System Discharge

$\begin{array}{lcllr}\text { Temp }{ }^{\circ} \mathrm{F} & \mathrm{m} / \mathrm{nc} & \mathrm{m} / \mathrm{nc} & \mathrm{m} / \mathrm{nc} & \leq 190 \\ \text { Temp }{ }^{\circ} \mathrm{C} & \mathrm{m} / \mathrm{nc} & \mathrm{m} / \mathrm{nc} & \mathrm{m} / \mathrm{nc} & \leq 88 \\ \mathrm{~N}_{2}(\mathrm{vol} . \%) & 100 & \mathrm{~nm} & \mathrm{~nm} & \mathrm{~nm} \\ \mathrm{H}_{2} \mathrm{O}(\mathrm{vol} \%) & \leq-76 \mathrm{dp} & \mathrm{nm} & \mathrm{nm} & \mathrm{nm} \\ \mathrm{H}_{2}(\mathrm{vol} . \%) & <4 & <4 & <4 & <0.005 \\ \mathrm{O}_{2}(\mathrm{vol} . \%) & <2 & <2 & <2 & <2\end{array}$

$\mathrm{nm}=$ not monitored

$\mathrm{m} / \mathrm{nc}=$ monitored, not controlled

$\mathrm{dp}=$ dew point, ${ }^{\circ} \mathrm{F}$

Section of this

document contain-

ing discussion

I I

II

I I

I I I

IV

$\begin{array}{ccc}170 \text { to } 190 & 230 \text { to } 250 & \pm 3 \\ \mathrm{~m} / \mathrm{nc} & 110 \text { to } 121 & \pm 2 \\ \mathrm{~nm} & 100 & -- \\ 100(1 \mathrm{iq}) & <-55 \mathrm{dp} & -- \\ \mathrm{m} / \mathrm{nc} & \mathrm{nm} & -- \\ \mathrm{nm} & \mathrm{nm} & --\end{array}$


zero before steaming is started. Since the thermal conductivity type meters also detect other gasses (although not to the same very low concentration as hydrogen), these gases must be at low levels in order to zero the meters. Therefore, total gas impurities in the nitrogen will probably be less than $50 \mathrm{ppm}$ before steaming is initiated.

The upper limit of $4 \%$ hydrogen in nitrogen was based on a misunderstanding. It is true that a $4 \%$ hydrogen mixture in air will be flamable, but hydrogen in any concentration in nitrogen could be safely vented in air without any hazard whatsoever, since any mixture ratio would lower the final hydrogen concentration below $4 \%$. The lowest possible concentration of hydrogen in nitrogen which can produce a flammable mixture with air is $5.3 \%$; even this requires that exactly $75 \%$ nitrogen and $25 \%$ air be mixed. Either more or less air results in a non-flammable system. At $6 \%$ hydrogen in nitrogen, flammable mixtures occur with 25 to $25 \%$ air, though not outside these mixing ratios. A hazardous situation can exist in the vessel only if large amounts of air are left in, while at least $8 \%$ steam is injected, which implies simultaneous failure of many instruments and violation of many procedures. Once inerting is accomplished, up to $5.3 \%$ hydrogen in the nitrogen can be safely vented without any flammability hazard.

In determining the initial concentration of steam to be used, it is assumed that the component may have large surfaces and/or frost areas present. This is generally true and implies that a low concentration (approximately 1\%) of water should be used to be conservative. After the large areas have reacted (or the hydrogen meter indicates that they are not present), the feed may be quickly raised to $5 \%$ for the majority of the processing. When the reaction has been completed (hydrogen less than 5 ppm at normal nitrogen feed rates, which is nearly the lower detection limit), it is well to raise the steam concentration to a high value (that is, greater than 30\%) and wait several hours to be sure that the hydrogen concentration is still zero. This will prevent flooding of small ammounts of sodium that might still be reacting. 
The high steam concentration may be obtained in several ways. One way is to maximize the steam flow and/or minimize the nitrogen flow. Another way is to partially flood the vessel and sparge the gas through the water to raise its moisture content. Any method that is acceptable from an equipment viewpoint is satisfactory to accomplish the purpose.

The initial reaction surface temperature should be at least $146^{\circ} \mathrm{F}$ because of the following reaction which occurs at that temperature.

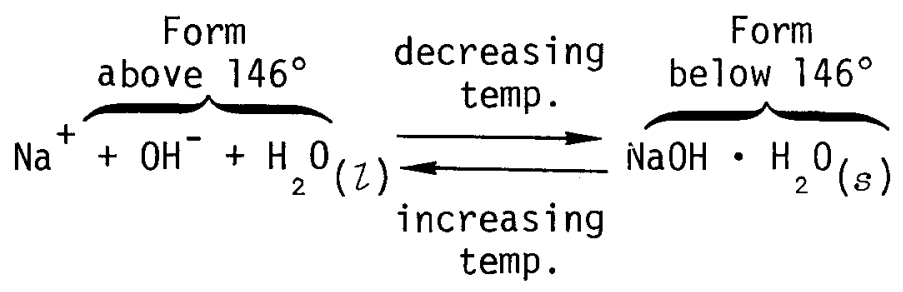

This reaction leads to large instabilities in the consumption rezction because of the loss or gain of water at the consuming surface. This was probably the major cause of spikes where processing was under $150^{\circ} \mathrm{F}$ and has been vividly demonstrated in the laboratory to be destabilizing.

The usual inaccuracies in instrumentation coupled with the unknowns about the temperature at all parts of different equipment configurations led to the judgment to use $160^{\circ} \mathrm{F}$ as the specified starting temperature. A temperature as low as $150^{\circ} \mathrm{F}$ could be used if the equipment and procedures insured that all surfaces were truly at least $150^{\circ} \mathrm{F}$.

The reasoning for the $190^{\circ} \mathrm{F}$ maximum temperature was similar. The sodium surface temperature during reaction may be $10-15^{\circ} \mathrm{F}$ hotter than ambient, but the sodium must not be allowed to melt. If it does, the available reaction area can drastically change and this has been demonstrated repeatedly in the laboratory as an unstabilizing factor.

The $10^{\circ} \mathrm{F}$ increase in operating temperature has proved very effective in dampening reaction rate oscillation. Temperature increases significantly 
below this value probably would not be effective in accomplishing the stabilizing action. Higher increases would unnecessarily use up the available temperature range for restabilizing the reaction at a future time. Since it is the reacting surface temperature that is important, and the gas has quick access to those surfaces, stability is obtained very readily. It is of no importance that the bulk interior temperatures of a large component may not make the $10^{\circ} \mathrm{F}$ increase for several hours.

\section{EXTENDED RANGE OF VARIABLES}

In reviewing the present criteria, changes in operating temperatures do not appear productive. The absolute limits are $146-208^{\circ} \mathrm{F}$, as previously mentioned. Enlarging the $160-190^{\circ} \mathrm{F}$ condition to come closer to the absolute limit would not appear to effect any practical saving in equipment, design, operation, or procedures.

The limits on the oxygen and hydrogen could safely be enlarged without requiring better instrument accuracy or tighter procedures. In practice, the initial impurity level will be very close to zero. By the same token, the chance of a real component operating at a hydrogen concentration above $1 \%$ is smal1.

Changes in water vapor concentration could significantly reduce the vapor phase processing time. Since the reaction rate is dependent on the 1.2 power of concentration, raising the water from $5 \%$ up to $10 \%$ would increase the rate by a factor of 2.7 and reduce the vapor reaction time by $63 \%$. However, this may only amount to a $20-30 \%$ decrease in total processing time from loading - through inerting, through vapor, through rinse, through drying -- to unloading.

Early developments showed much greater instability at the higher water concentrations (above 15\%). The feedback concept was tested only with $5 \%$ water. Concentrations up to $10 \%$ may be feasible but would definitely require development work to confirm stability. 
It is of interest to note that European systems run at much higher water concentrations (in either the steam or mist mode) and do have indications of instability. However, they have chosen to disregard this and apparently do not consider it a problem. If there were no undrained sodium pools, low water concentration would be unnecessary and a suggested operating level would be near 100\% water vapor. Although designers generally seek to avoid pools, there is some risk of small ones occurring from time to time. These may manifest themselves in bangs, pops, etc., high temperatures, or other indications of a rapid uncontrolled reaction. Conservatism indicates remaining with the lower concentration, slower processing.

Starting at $190^{\circ} \mathrm{F}$ has often been suggested to avoid instability and simplify the process. This high temperature start offers 1ittle savings in capital equipment or procedures and merely slows the reaction rate while not preventing possible instabilities. In addition, it eliminates the option of taking effective action to regain a stable situation.

In summary, the vapor phase of the WVN process is confined by a number of practical constraints which prevent major changes within the moist gas concept. The most lucrative improvement would be a modest increase in the normal water vapor concentrations. 


\section{RINSING}

\section{A. CREVICE STUDIES}

Crevices were considered a very difficult configuration to clean, and cleaning could be done most effectively in the rinse phase. The majority of the testing was done in 1972-73 when primary concerns were the Intermediate Heat Exchanger (IHX) and In-Vessel Handling Machine (IVHM) crevice problems (which were typical of many other components) and design changes which might be made to improve the situation. One study showed that crevices could be effectively and repeatedly cleaned if the reactants had access to the sodium.

A series of tests ${ }^{(7)}$ on crevices from 1 to 29 mils wide revealed a number of interesting points (see Figures 8 and 9 and Tables 5 and 6):

- Increased water vapor concentration gave faster penetration into a given crevice.

- Hot $\left(185^{\circ} \mathrm{F}\right)$ water, as opposed to ambient water, gave penetration rates 10-100 times faster.

- Removal depth increased with the log of time.

- Removal from crevices smaller than $1 \mathrm{mil}$ tended to be erratic.

- Orientation of crevices was important -- the open-end-down attitude was the most difficult to clean.

The equation developed for gas phase crevice penetration was:

$$
\begin{aligned}
& k=0.50+1.527 \ln t \\
& k=\text { inches removed } \\
& t=\text { hours }
\end{aligned}
$$

which is for the condition of $100 \%$ steam at $215-250^{\circ} \mathrm{F}$ with $26-56$ mil gaps. 


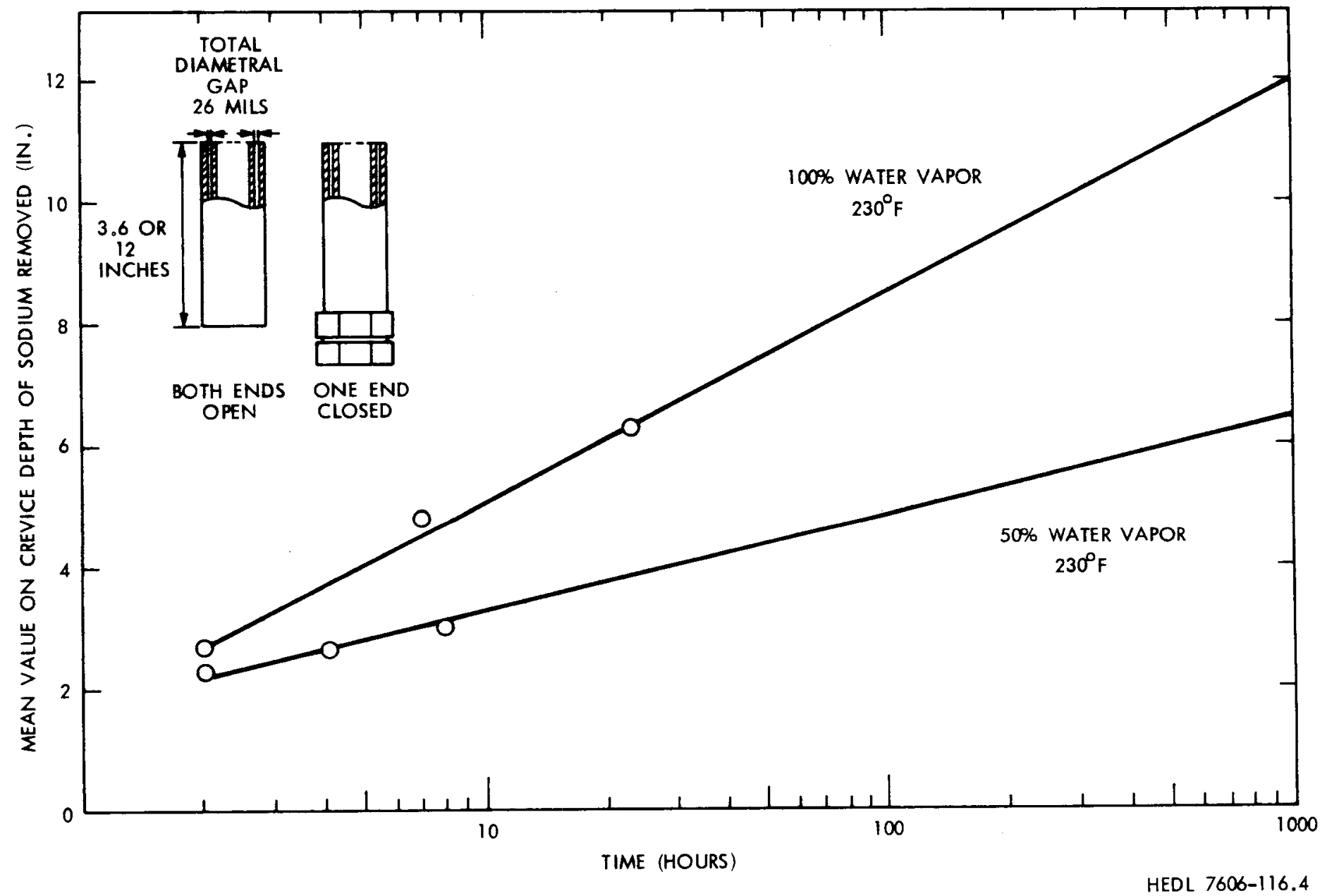

FIGURE 8. Time Required to Remove $100 \%$ of Sodium from 13-Mit Gap Crevices 


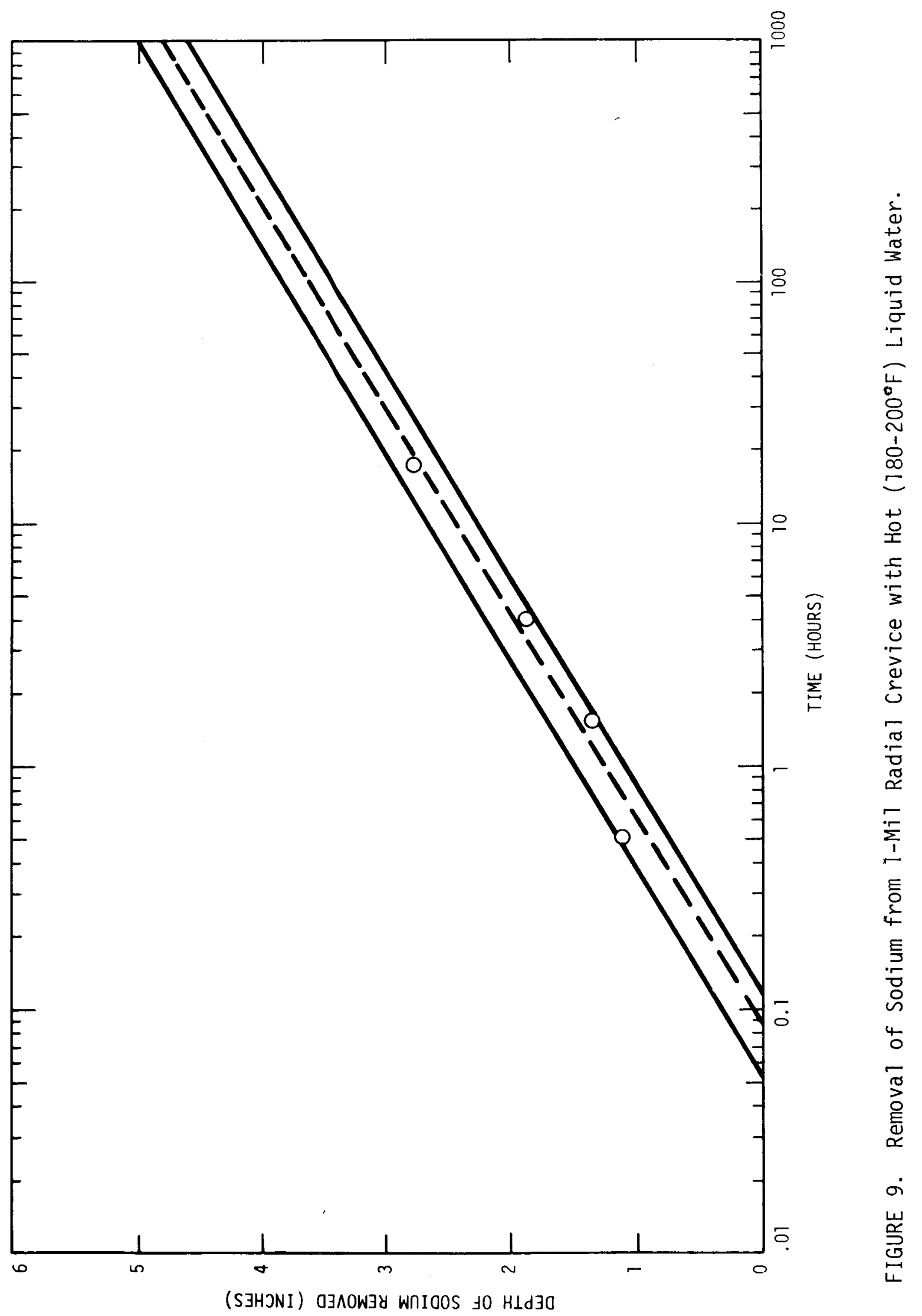


TABLE 5

EFFECTIVE SODIUM REMOVAL FROM CREVICES WITH 4-HR EXPOSURE

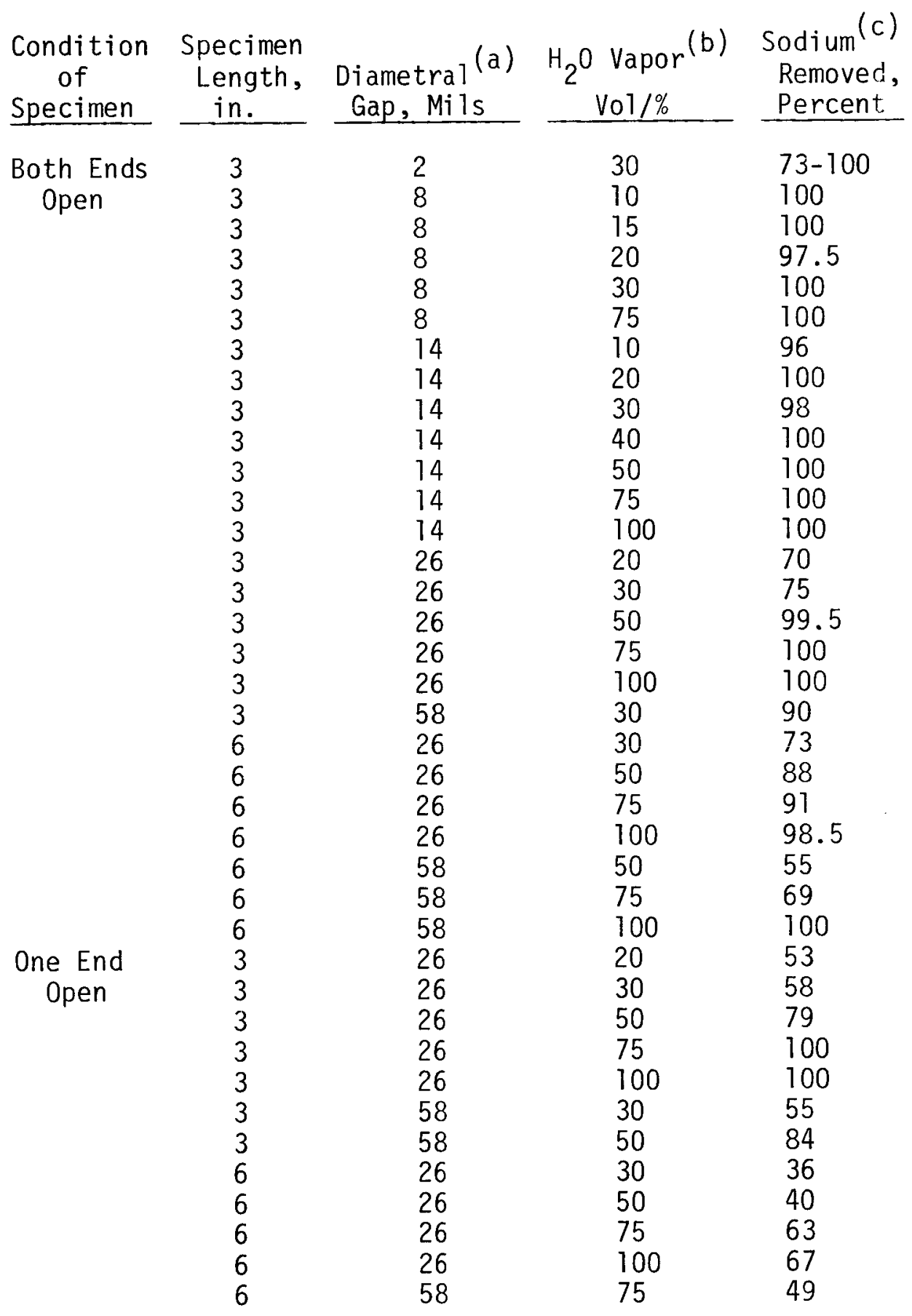

a. Radial gap equals average gap half that 1 isted.

b. Measured by Flowmeter.

c. Calculated Values. 
TABLE 6

EFFECTIVE SODIUM REMOVAL FROM 13-MIL CREVICES ${ }^{(a)}$ FOR VARIOUS TIMES

\begin{tabular}{|c|c|c|c|}
\hline $\begin{array}{c}\text { Specimen } \\
\text { Length, } \\
\text { in. } \\
\end{array}$ & $\begin{array}{c}\text { Mois ture, } \\
\text { Percent }\end{array}$ & $\begin{array}{c}\text { Time, } \\
\text { hr } \\
\end{array}$ & $\begin{array}{l}\text { Sodium } \\
\text { Removed, } \\
\text { Percent }\end{array}$ \\
\hline $\begin{array}{l}6 \\
6 \\
6 \\
6 \\
6 \\
6 \\
6 \\
6 \\
6 \\
6 \\
6 \\
6\end{array}$ & $\begin{array}{l}30 \\
30 \\
30 \\
30 \\
50 \\
50 \\
50 \\
50 \\
50 \\
100 \\
100 \\
100\end{array}$ & $\begin{array}{l}1 \\
2 \\
4 \\
18 \\
1 \\
2 \\
4 \\
8 \\
18 \\
2 \\
4 \\
6\end{array}$ & $\begin{array}{l}70 \\
67 \\
73 \\
100 \\
65 \\
75 \\
88 \\
100 \\
100 \\
88 \\
98.5 \\
100\end{array}$ \\
\hline
\end{tabular}

a. $26 \mathrm{mil}$ diametral equals average gap width of $13 \mathrm{mil}$

\section{B. RINSE STUDIES}

In early 1975 a number of low priority tests were conducted to determine the results of bulk rinsing. These tests were set up to measure only the effects of large surface areas and pools so there would be no confusion with logarithmic effect of crevices. Results were compared with the small amount of SRDA operating data.

The tests showed that surface rinsing was effective in a very short time (one residence time or less) and that agitation had little effect. The only case where turbulence was of value was where direct impingement was obtained on the nondrainable area to splash out the remaining caustic solution. Results confirmed that minimum volume rinses made the most efficient use of rinse water, and it was concluded that the most effective rinsing campaign might be as follows: 
1) One or two quick rinses to remove the majority of caustic and bring conductivity meters on scale.

2) One long rinse to allow for diffusion into and out of crevices and small pockets or pools.

3) One additional rinse for a quick "polish" to insure surface cleanliness.

With the experience of this and other crevice tests, it would be useful to examine the performance of some real components. In the case of the IVHM, the rinses were changed every few hours but the rinse conductivity did not improve very rapidly. This was probably due to the myriad of large and small crevices and pockets the caustic had to diffuse from. In retrospect, continuing the rinses for some arbitrarily longer time (24 to $48 \mathrm{hr}$ ) may not have extended the actual cleaning time much but would have used less water. Since the IVHM is fairly open, access of rinse to all areas was presumed to be good.

The IHX tube bundle model was another item cleaned in the large Alkali Metal Cleaning Facility (AMCF) vessel. After one long rinse, there was caustic in the interior which had not been present in the previous test during which it had been rinsed for the same length of time but through many more cycles. It was reasoned that, because of the shrouding, there was no mechanical interchange of fluid, so the rinsing was not as effective. On a successive try the rinse was raised and lowered above and below the model every $24 \mathrm{hr}$. This amounted to a "new" rinse every day with a mechanical drain and refill of all voids. For the large vessel, little extra water was used over the initial fill volume. This technique removed al1 caustic from the model.

\section{PARAMETERS}

From the foregoing it was determined that high temperatures are beneficial to rinsing. The reaction rate of water with sodium increases, 
the solubility of sodium products in water increases, the diffusivity of sodium compounds in water increases, and the viscosity of water decreases. A11 of these speed up sodium removal operation.

The water concentration should be as high as possible. The early crevice test showed that the present processing $\left(160^{\circ} \mathrm{F}, 5 \%\right.$ water during vapor phase) was ineffective; $100 \%$ steam at over $215^{\circ} \mathrm{F}$ was required to give reasonable rates. Some tests in liquid water showed that a temperature of $185^{\circ} \mathrm{F}$ was effective.

At this point a judgment was made to attempt crevice cleaning during the rinse phase only rather than extending the vapor phase to high temperatures and concentration. Water temperatures over $212^{\circ} \mathrm{F}$ would require a pressurized vessel and introduce a number of mechanical difficulties. In addition, there would be the problem of nearing the caustic stress corrosion cracking condition for some areas of the component. If a gas sparge is maintained at temperatures over $200^{\circ} \mathrm{F}$, large quantities of condensate occur in the vent piping of the cleaning system. Therefore, the $180-200^{\circ} \mathrm{F}$ range was picked as a temperature high enough to be effective but low enough to simplify the requirements for process hardware.

The initial rinse temperature originally had been ambient. It was reasoned that this would decrease the sodium-water reaction rate somewhat and, therefore, be a safer way of flooding the component. However, it would also freeze high concentration caustic in crevices and puddles which would take more time to redissolve even when hotter rinses were used. Since the experience with better gas phase control showed that small amounts of remaining sodium could be detected before flooding, the initial rinse temperature was changed from ambient to $180^{\circ} \mathrm{F}$.

A high rinse water resistivity endpoint was chosen as the most realistic for various component configurations. Significant amounts of caustic were not found when the circulating rinse water maintained a Grade B conductivity. The number (a few or many) or duration (a few hours 
or a few days) of rinses were not felt to be amenable to facility design but should be the decision of the operator and would vary from component to component. It was necessary, therefore, to provide some rinse flexibility in the facility design.

The major rinse variable subject to design manipulation was temperature. Low ambient temperatures saved little in the way of equipment and greatly extended processing time. Higher temperatures speeded up rinsing but required pressurizing of the system and components.

Agitation was a possiblity for speeding the rinsing in critical areas, but it would be difficult to design a general device to impinge the rinse at the right place or places on a variety of components, many of which are very effectively shrouded. A simpler method would be twin tanks where the rinse could be pumped back and forth to fill and drain the component volumes without using any new water. 


\section{DRYING}

\section{A. THEORETICAL CONSIDERATIONS}

There are three main methods of drying in the WVN process: vacuum, hot-gas-only, or a combination of the two. The fastest drying method is preferred to minimize processing time, but there is no clear-cut advantage to any method for the general case.

Evaporation of water is difficult because of its high heat of vaporization ( $970 \mathrm{Btu} / \mathrm{hr}$ at $212^{\circ} \mathrm{F}$ and 1036 at $100^{\circ} \mathrm{F}$ ). It is also complex because it involves the two mechanisms of heat and mass transfer simultaneously. The use of a vacuum greatly increases the mass transfer rate of water vapor from a puddle, but the movement of water soon stops unless the needed amount of heat is added to the pool. The only method of heat transfer under a vacuum is by radiation which gives very low heat fluxes at the temperatures expected in normal operation $\left(100-200^{\circ} \mathrm{F}\right)$.

On the other hand, the use of dry gas provides a steady means of heat input to the component even though it inhibits the mass transfer rate. While heat transfer by natural convection is poor, it is several times better than could be expected by radiation under the same temperature differences.

The choice of method then depends more upon the peculiarities of each component being processed. A component with a large mass of metal (relative to the water) that is in good thermal contact with the water may dry more quickly under a vacuum. An example would be the IVHM where a small amount of water may be present both in counter bore holes and in crevices of massive parts. In this case, there is more than enough thermal energy stored in the metal to evaporate all the water quickly. 
On the other hand, a component with a small mass in relatively poor thermal contact with water would dry much quicker by hot gas. An example of this would be the baffle sections of many components or the IHX where the tube bundle is shrouded. Tubes in inner areas would be "blind" to radiant heat transfer under a vacuum, but would absorb heat rapidly from a circulating gas.

Other components may be intermediate in drying performance with either operation, or they may be extremely good in one particular mode depending on their configuration -- surfaces that may act as good heatgathering fins in radiant or convective transfer.

With this in mind, it is now worthwhile to look at the various equipment experiences.

\section{B. EQUIPMENT EXPERIENCE}

During sodium removal testing of the pump bearing pocket in SRDA, one test was made of a vacuum-versus-gas drying cycle. The two modes were:

1) Three $15-\min$ cycles of $180^{\circ} \mathrm{F}$ nitrogen interrupted by two 15-min vacuum cycles for a total of $75 \mathrm{~min}$, and

2) $90 \mathrm{~min}$ of $180^{\circ} \mathrm{F}$ nitrogen.

For this particular configuration of crevices (the predominant feature of this model), the first cycle was more effective. This was not surprising since most combination cycles do show better performance over either pure drying or pure vacuum.

Experience in AMCF was more limited. There have been no direct tests of vacuum-only versus gas-only versus vacuum-gas combinations. During cleaning of the IVHM a hot-gas-only cycle was used and found to be effective -- no water was found in any part of the machine. The moisture content of 
the exit gas had remained at 300-350 ppm for a number of hours before the component was removed. A pool of water was found later in some connecting piping, and this must have been the source of the low-level moisture. This demonstrated that pools of water can actually be detected in large systems.

A dump heat exchanger (DHX) was recently cleaned with ethanol. Some preliminary drying was attempted with essentially ambient temperature gas. The gas was initially hot but because of the heat transfer characteristics of the device, it quickly cooled to ambient. A shift was made to vacuum and drying was successfully terminated after a low pressure had been reached. A sample of the backfilled (but not recirculated) gas showed less than 1 ppm ethanol, but no visual inspection was possible. Presumably this demonstrated that vacuum could be effective on large objects although in this case it should be understood that the object was very effectively warmed by the ambient air.

A short study was conducted in SRDA on the three drying modes: vacuum-only, gas-only, and vacuum-gas combination. The component was a 12-in. diam pot filled with water sitting on a grate in the vessel (see Table 7 for the resulting data). In this case the vacuum mode was more effective, but the component was hardly typical. A simple pot 1/8-in. thick had a mass much less than the water contained. Since there was little metal mass, the experiment would tend to emphasize the biggest difference between the two drying modes. It should also be noted that the grating upon which the pot sat acted as a much more effective heat-gathering fin in the vacuum mode than in the natural gas convection mode. 
TABLE 7

RESULTS OF SRDA DRYING MODE TESTS

\begin{tabular}{|c|c|c|}
\hline Mode & $\begin{array}{l}\text { Pot or Wet Bulb } \\
\text { Temperature, }{ }^{\circ} \mathrm{F}\end{array}$ & $\begin{array}{c}\text { Evaporation Rate, } \\
\text { 1b/water } / \mathrm{hr}-\mathrm{ft}^{2} \\
\text { of Water Area } \\
\end{array}$ \\
\hline Hot Gas & 150 & 0.40 \\
\hline Vacuum & 80 & 0.69 \\
\hline Mixed & $80 / 150$ & 0.50 \\
\hline
\end{tabular}

C. PARAMETERS

From a practical viewpoint there are several considerations. First, in real components the difference in evaporation rates between the several modes would tend to be less than shown by any specific test or example. Second, the pockets of water in components will usually be less than one inch deep, thereby giving fairly short drying times in either mode. Third, the equipment for the hot-gas mode is already in being as part of the WVN process. Fourth, drying requires additional equipment, maintenance, and procedures which add to the installed and operating cost of the facility. Pursuant to this, it should be noted that in large real systems it will take on the order of at least one hour to change valve line-ups, shutdown/ startup equipment, etc. This effort is required to change from hot-gas to vacuum mode, and the same time is required to change back again.

For the present, the hot-gas-only mode was selected as the simplest under the variety of conditions that would probably be encountered in the normal cleaning facility. A vacuum mode could certainly be used in addition or in combination with hot-gas drying. In view of the marginal decrease in total processing time a vacuum drying system might give versus the extra cost, it seems reasonable to not include vacuum drying as a part of the WVN process. 


\section{REFERENCES}

1. J. Krey, Z. Physik Chemie, Neue Folge, 81, 252, (1972).

2. "HEDL Sodium Removal Program Quarterly Report," January-March 1975, TME 75-3.

3. "HEDL Sodium Removal Program Quarterly Report," Apri1-June 1975, TME 75-64.

4. "Sodium Technology Technical Progress Report," Ju1y, August, September 1975, TME 75-117.

5. Combustion, Flames and Explosions of Gases, B. Lewis and G. von Elbe, 2nd Edition, Academic Press, 1961. A1so, data cited is found in Limits of Flammability of Gases and Vapors, H. F. Coward and G. W. Jones, U.S. Bureau of Mines BuT1. No. 503, 1952.

6. Results of Sodium Removal Tests in IHX Locking in Subassemblies Using the Moist Nitrogen, Alcohol and Evaporation Processes, February 1973, HEDL-TME-72-150.

7. Rate of Sodium Removal from Crevices in FFTF/LMFBR Equipment, November 1973, HEDL-TME-73-32. 